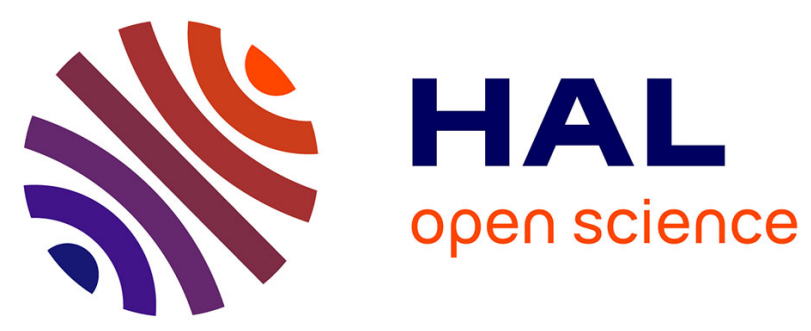

\title{
Comprehensive conformational study of key interactions involved in zearalenone complexation with beta-d-glucans
}

\author{
Alexandros Yiannikouris, Gwenaëlle André-Leroux, Alain Buleon, Georges \\ Jeminet, Isabelle Canet, Jean-Marie François, Gérard Bertin, J Pierre Jouany
}

\section{To cite this version:}

Alexandros Yiannikouris, Gwenaëlle André-Leroux, Alain Buleon, Georges Jeminet, Isabelle Canet, et al.. Comprehensive conformational study of key interactions involved in zearalenone complexation with beta-d-glucans. Biomacromolecules, 2004, 5, pp.2176-2185. hal-02676454

\section{HAL Id: hal-02676454 \\ https://hal.inrae.fr/hal-02676454}

Submitted on 31 May 2020

HAL is a multi-disciplinary open access archive for the deposit and dissemination of scientific research documents, whether they are published or not. The documents may come from teaching and research institutions in France or abroad, or from public or private research centers.
L'archive ouverte pluridisciplinaire HAL, est destinée au dépôt et à la diffusion de documents scientifiques de niveau recherche, publiés ou non, émanant des établissements d'enseignement et de recherche français ou étrangers, des laboratoires publics ou privés.

\section{다(1)(2)}

Distributed under a Creative Commons Attribution - ShareAlikel 4.0 International 


\title{
Comprehensive Conformational Study of Key Interactions Involved in Zearalenone Complexation with $\beta$-D-Glucans
}

\author{
Alexandros Yiannikouris, ${ }^{\dagger, \ddagger}$ Gwénaëlle André," Alain Buléon, ${ }^{\perp}$ Georges Jeminet, ${ }^{\#}$ \\ Isabelle Canet, ${ }^{\#}$ Jean François, $\$$ Gerard Bertin, ${ }^{\ddagger}$ and Jean-Pierre Jouany ${ }^{*}, \dagger$ \\ UR1213 INRA, Unite de Recherches sur les Herbivores, Centre de Clermont-Theix, \\ 63122 St-Genès Champanelle, France, Unité de Biochimie Structurale, Institut Pasteur, \\ 75224 Paris, France, UMR-CNRS 6504, Laboratoire de Synthèse et Étude des Systèmes à Intèret \\ Biologique, Université Blaise Pascal - Clermont-Ferrand II, 63177 Aubiere Cedex, France, UR783 INRA, \\ Unite de PhysicoChimie des Macromolécules, 44316 Nantes Cedex 03, France, and UMR-CNRS 5504, \\ UR-INRA 792, INSAT, 135 avenue de Rangueil, 31077 Toulouse Cedex 4, France
}

Received April 15, 2004; Revised Manuscript Received July 20, 2004

\begin{abstract}
The $\beta$-D-glucans from the cell wall of Saccharomyces cerevisiae have shown in vitro affinity for zearalenone. For this reason, their utilization as dietary adsorbent, to reduce the bioavailability of zearalenone, is of practical interest. Our study used powerful devices to elucidate the spatial conformation and molecular sites of interaction between ZEN and $\beta$-D-glucans. In this respect, ${ }^{1} \mathrm{H}$ NMR spectroscopy implicated the hydroxyl groups of the phenol moiety of zearalenone in the complexation by laminarin, a pure $\beta$-(1,3)-D-glucan. $\mathrm{X}$-ray diffraction determined that laminarin displays the conformation of a single-helix with six $\beta$-D-glucopyranose residues per turn. At this stage, molecular modeling was useful to locate the interaction sites and to propose highly probable complexes of zearalenone with laminarin fragment. Interestingly, the $\beta$-(1,3)-D-glucan chain favors a very stable intra-helical association with zearalenone, nicely stabilized by $\beta$-(1,6)-D-glucans side chains. Both hydrogen bonds and van der Waals interactions were precisely identified in the complex and could thus be proposed as driving interactions to monitor the association between the two molecules.
\end{abstract}

\section{Introduction}

Zearalenone (ZEN), a 6-(10-hydroxy-6-oxo-trans-1-undecenyl)- $\beta$-resorcylic acid lactone, studied here, is a nonsteroid estrogenic toxin produced by numerous Fusarium species that may, along with other mycotoxins, contaminate grains (wheat, barley, grain sorghum, corn) and grain products (flour, bread, and processed commercial feed) or may transit into milk and edible animal tissues. ${ }^{1} \mathrm{ZEN}$ is responsible for negative effects on reproductive performance due to its estrogenic properties. The lack of practical solutions to control mycotoxin contamination in the field or in harvested products has increased our interest on methods to directly protect animals fed on nondetected contaminated feeds and consequently to protect the consumers of edible animal products. ${ }^{2}$ In this respect, there have been reports of adsorbents used to reduce mycotoxin bioavailability in the digestive tract and consequently their detrimental effects on animals. Thus, inorganic materials such as clays, bentonites, and aluminosilicates have been suggested to bind mycotoxins, ${ }^{3,4}$ but they showed limited efficacy against a wide

* To whom correspondence should be addressed. Phone: + 33 (0)4 73 6240 54. Fax: + 33 (0)4 736246 59. E-mail: jouany@clermont.inra.fr. UR1213 INRA, URH.

$\doteqdot$ Alltech-France, 2-4 avenue du 6 Juin 1944, 95190 Goussainville, France.

"Institut Pasteur.

$\perp$ UR783 INRA, UPCM.

\# UMR-CNRS 6504, SESIB.

§ UMR-CNRS 5504, UR-INRA. range of toxins and, furthermore, exhibited adsorptive properties toward certain nutrients and could also be contaminated with dioxin and heavy metals. As a result, organic compounds such as yeast ${ }^{5-8}$ or bacterial ${ }^{9-11}$ cell walls have been investigated for their ability to complex with several mycotoxins without detrimental effects on environment or on the bioavailability of certain nutrients.

Previous in vitro experiments, carried out at body temperature $\left(+37-39^{\circ} \mathrm{C}\right)$, studied complex-forming abilities when constant quantities of yeast cell wall components were mixed with an increasing amount of ZEN. The results demonstrated that, in addition to their well-known stimulating abilities for the immune system, $\beta$-D-glucans extracted from the cell wall of Saccharomyces cerevisiae, which are composed of linear chains of $\beta$-(1,3)-D-glucans branched with $\beta$-(1,6)-D-glucan side chains, have adsorption properties (affinity rates up to 50\%) in aqueous solution toward ZEN. ${ }^{12,13}$ The adsorption process is greatly dependent on the three-dimensional organization of $\beta$-D-glucans presumably involving the occurrence of single and/or triple-helix conformations of $\beta$-(1,3)-D-glucans. The perturbation of these structures has been tested in acidic, neutral, and basic environmental conditions, by the use of pure $\beta$-(1,3)-Dglucans, branched or not with $\beta$-(1,6)-D-glucans, such as curdlan (insoluble homopolymer of $\beta$-(1,3)-D-glucans), laminarin (soluble $\beta$-(1,3)-D-glucans poorly branched with $\beta-(1,6)$ D-glucans), pachyman (insoluble $\beta$-(1,3)-D-glucans highly branched with $\beta$-(1,6)-D-glucans), or pustulan (insoluble 
homopolymer of $\beta$-(1,6)-D-glucans). ${ }^{14}$ Acidic and neutral conditions were the most suitable conditions for maximal occurrence of complex with $\beta$-(1,3)-D-glucans, whereas alkaline medium conditions, due to their destabilizing effect on $\beta$-D-glucans spatial organization, ${ }^{15,16}$ decreased complexation efficacy. The adsorptive properties could be partially recovered at alkaline $\mathrm{pH}$ when $\beta$-(1,6)-D-glucan branching was important. Furthermore, release of ZEN in the medium, following the removal of all nonbound toxins in the surrounding medium, led to the characterization of the complexation equilibrium between free toxins and toxins bound to $\beta$-D-glucans.

To enhance our understanding at a molecular level of the chemical and structural factors involved during the $\beta$-Dglucans and ZEN complexation mechanism, ${ }^{1} \mathrm{H}$ liquid RMN investigations were carried out with the soluble $\beta$ - $(1,3)$-Dglucans laminarin and ZEN. The spectral changes induced by the complexation of the two molecular entities were carefully characterized. Since the proton spectrum of $\beta$-Dglucans refers to numerous not fully assigned ${ }^{17}$ hydrogens (differing in the $\beta$-D-glucopyranosyl unit and in their position in the polymer), the high-resolution NMR signal ${ }^{18}$ obtained for ZEN was used as a signal reference to spy on the interaction between the two entities. X-ray diffraction experiments elucidated the spatial organization of laminarin and curdlan. When compared to the three-dimensional network of yeast cell wall $\beta$-D-glucans, the reliability of our previous hypothesis involving single and triple-helix conformations was confirmed. These data, in conjunction with molecular modeling techniques, allow us to make conclusive remarks on the three-dimensional structure and the steric accessibility of the ZEN molecule inside the polysaccharide chain, the nature of the interaction, and the functional groups of primary importance involved in the docking process.

\section{Materials and Methods}

Liquid NMR Investigations of the Interaction Between ZEN and Pure $\boldsymbol{\beta}$-D-Glucans. Liquid NMR experiments were carried out in solution $(300 \mathrm{~K})$ on a Bruker Avance 400 spectrometer, using laminarin as unique source of soluble $\beta$-D-glucans and ZEN, each in different solvents. ${ }^{1} \mathrm{H}$ and ${ }^{13} \mathrm{C}$ spectra, recorded at 400 and $100 \mathrm{MHz}$ respectively, were carried out in acetonitrile- $d_{3}\left(\mathrm{CD}_{3} \mathrm{CN}\right)$ for $\mathrm{ZEN}$ and in $\mathrm{D}_{2} \mathrm{O}$ for laminarin to achieve the resonance assignment. Bidimensional ${ }^{1} \mathrm{H}-{ }^{1} \mathrm{H}$ and ${ }^{1} \mathrm{H}-{ }^{13} \mathrm{C}$ COSY correlations were used for this, together with monodimensional ${ }^{1} \mathrm{H}$ and ${ }^{13} \mathrm{C}$ measurements (not discussed here).

Next, ${ }^{1} \mathrm{H}$ spectra were recorded in dimethyl sulfoxide or DMSO- $d_{6}\left(\left(\mathrm{CD}_{3}\right)_{2} \mathrm{SO}, 99.8 \%\right)$, which appeared to be the only common NMR solvent for ZEN and laminarin. However, a DMSO effect has been documented for $\beta$-D-glucans ${ }^{15}$ leading to conversion of triple or single helical structures into random coil structures. Similarly, it has been shown that DMSO molecules were able to form hydrogen bonds with the $\mathrm{C}(4)-$ $\mathrm{OH}$ and $\mathrm{C}(6)-\mathrm{OH}$ hydroxyl groups of laminarin, inducing the formation of single disordered chains. ${ }^{19}$ In this respect, DMSO could have a negative impact upon the complexation abilities of $\beta$-D-glucans, since this property seemed to be greatly dependent on the presence of an organized structure such as helix.

In DMSO, NMR spectra for ZEN and laminarin were clearly separated when they were mixed at the same weight concentration, allowing observation of spectral variations due to complex formation. However, even under drastic [ZEN]/ [laminarin] ratio changes, no spectra modification were registered.

Thus, a specific protocol was set up to limit the competition between DMSO molecules and ZEN using an in vitro technique to estimate the ZEN complex-forming capacity of $\beta$-D-glucans. ${ }^{20}$ The final experiments were carried out as followed: ZEN previously dissolved in acetonitrile was added to $10 \mathrm{~mL}$ of a Milli- $\mathrm{Q}^{\text {uft }}$ solution of laminarin in tubes at a concentration of $50 \mu \mathrm{g} / \mathrm{mL}$. After shaking at $640 \mathrm{rpm}$ with an orbital shaker during $1.5 \mathrm{~h}$ at $+39^{\circ} \mathrm{C}$, samples were cooled on a bath of 2-propanol kept at $-30^{\circ} \mathrm{C}$ before freezedrying on a Lyovac GT2 during $72 \mathrm{~h}$, to avoid crystallization.

The powder containing the [laminarin + ZEN] complex was solubilized in $500 \mu \mathrm{L}$ of DMSO- $d_{6}$ to reach the concentration of $1 \mathrm{mg} / \mathrm{mL}$ for both molecules. The ${ }^{1} \mathrm{H}$ NMR spectra of the [laminarin + ZEN] sample were then recorded and compared with the spectra of separated components in the same conditions in order to characterize changes induced by the interaction.

Note: ZEN, like all mycotoxins, is a hazardous chemical and must be handled with extreme care. Protective clothing, gloves, a fume hood and goggles are essential to prevent exposure to mycotoxins.

Wide-Angle X-ray Diffraction Patterns of $\beta$-D-Glucans. $\mathrm{X}$-ray analyses were performed on two molecules of $\beta$-Dglucans, laminarin, and curdlan, at two hydration levels: in their semicrystalline form and in their wetted form. The laminarin and curdlan powders were hydrated over a solution of barium chloride ( $a_{\mathrm{w}}=0.9$ at $25^{\circ} \mathrm{C}$ during 5 to 8 days) until equilibrium of the wet sample mass was reached. X-ray diffraction measurements were carried out on the two $\beta$-Dglucan molecules in semicrystalline and hydrated forms at ambient temperature using Inel X-ray equipment (XRG 3,000 , Inel, France) operated at $40 \mathrm{kV}$ and $30 \mathrm{~mA}$. The $\mathrm{Cu}$ $\mathrm{K} \alpha 1$ radiation $(\lambda=0.154 \mathrm{~nm})$ was selected using a quartz monochromator. Samples of around 20-30 mg were sealed between tape foils to prevent any significant change in water content during measurements. Diffracted intensities were monitored over a $2 \mathrm{~h}$ exposure period by a $120^{\circ}(2 \theta)$ curve position sensitive detector (CPS 120, Inel, France). The resulting diffraction diagrams were normalized to the same total degree of intensity between 3 and $30^{\circ}(2 \theta)$.

In Silico Molecular Mechanics Investigations. Molecular modeling was carried out on Silicon Graphics computers with Accelrys packages (Accelrys. Inc, San Diego, CA). Molecular displays and energy minimizations were performed using InsightII, Biopolymer, Analysis, Docking, and Discover modules. For all calculations, the CFF91 force-field with the steepest descent minimization was selected. This force-field is adapted to polysaccharide/protein or polysaccharide/ligand interaction studies and has been widely used to date. ${ }^{21,22}$

From the Construction of the Laminaribiose to the $\boldsymbol{\beta}$-(1,3)-D-Glucans. The most highly probable conformations 


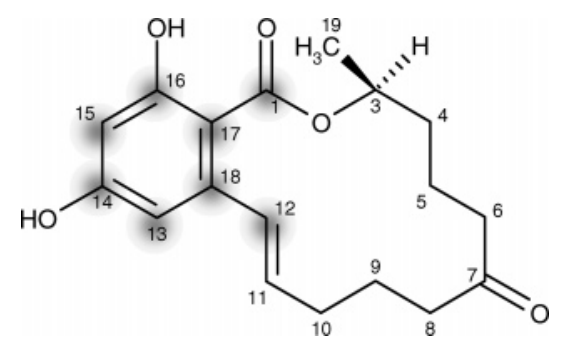

Figure 1. Constraints localization (in gray) applied to the initial stage of construction of the energy-minimized structure of ZEN molecule.

of a laminaribiose are mainly driven by the $\beta$-(1,3)-Dglycosidic linkage bonding the two glucose moieties. The linkage is fully described by the set of $[\varphi, \psi]$ dihedral angles. Each geometry has a distinct potential energy value for a given set of $[\varphi, \psi]$ dihedral angles. The complete conformational exploration of the dimeric $\beta$-(1,3)-D-glucan fragment required the rotation of its two $[\varphi, \psi]$ dihedral angles so that the $\varphi$ and $\psi$ of the laminaribiose were successively rotated from $-180^{\circ}$ to $+180^{\circ}$ with an increment of $+10^{\circ}$. At every step, potential energy was roughly evaluated within a zero iteration minimization procedure. The resulting "adiabatic $[\varphi, \psi]$ map" plots potential energy versus $[\varphi, \psi]$ values and led to a relevant description of the low energy conformations of the disaccharide. The low energy conformations were built taking special care in the positioning of the hydroxyl groups at $C(6)$ and $C\left(6^{\prime}\right)$, then minimized within a consistent 10,000 iterations procedure. The lowest energy conformation of the dimer served as reference for further elongation. Repeating its $[\varphi, \psi]$ values up to 36 times led to a 5,868 Da helical polymer that was then minimized during 10,000 iterations.

From the Construction of the Gentobiose to the Branched $\boldsymbol{\beta}$-(1,6)-D-Glucans. Similarly, a $[\varphi, \psi, \omega]$ conformational map was calculated for the gentobiose (dimeric fragment of $\beta$-(1,6)-D-glucans). Dihedral angles varied from $-180^{\circ}$ to $+180^{\circ}$ with a step of $+10^{\circ}$ for each rotation time. The low potential energy populations were identified and their corresponding minimum energy conformations were optimized within a 10,000 iterations minimization. One to five $\beta$-D-glucopyranose residues in their lowest energy conformations of $\beta$ - $(1,6)$-D-glucans were then branched to the $\beta$-(1,3)-D-glucan chain via a $\beta$-(1,6) linkage. All of the six connection points of the helix turn were tested and built before being optimized with a 5,000 iterations minimization procedure.

ZEN Conformations. The ZEN molecule was also investigated through molecular mechanics taking into account all of the experimental data available from our previous NMR and X-ray studies, ${ }^{23}$ plus those given in the literature. ${ }^{18}$ Due to its conjugated aspect, the molecule displays mainly freedom degrees around carbons C(3) to C(12) (Figure 1). This region was to be particularly tested with different starting conformations. Consequently, the evaluation of the low energy for the ZEN conformations required three steps: (i) constraints were first applied on the $\mathrm{C}(13)$ to $\mathrm{C}(18)$ heavy atoms of the phenol moiety plus the $\mathrm{C}(1), \mathrm{C}(10)$, to $\mathrm{C}(12)$ atoms close to this ring for a 2,500 iterations minimization; (ii) next, the systems were relaxed without constraints for
1,000 iterations; (iii) the conformation(s) giving the lowest energy was further minimized within 5,000 iterations.

Formation of the [ZEN $+\boldsymbol{\beta}$-D-Glucans] Complex. The ZEN molecule was manually positioned in one of the cavities offered by the helical $\beta$-(1,3)-D-glucan polymer. All of the possible spatial orientations of the ZEN molecules, in interaction with the $\beta$ - $(1,3)$ helix, were investigated so that translations plus rotations as well as up and down positioning were carefully explored. Positioning was performed each time with special attention, so as to avoid any steric clash between the two entities. Any starting conformation that was obviously too far from any complexation position was discarded from the 10,000 iterations minimization.

Starting from the low energy complex(es) between the $\beta$-(1,3)-D-glucan helix and the ZEN molecules, the toxin was carefully repositioned inside the new cavity formed by the very close vicinity of the $\beta$ - $(1,6)$ - branched fragment of three to five $\beta$-D-glucopyranose rings. Sensible optimization positioning of the ZEN within the branched $\beta$-D-glucan was reiterated within a 10,000 iterations minimization.

\section{Results and discussion}

Liquid NMR Investigations of the Interaction between ZEN and Pure $\boldsymbol{\beta}$-D-Glucans. Molecular dynamics study of the $\beta$-(1,3)-D-glucan laminarin in various solvents ${ }^{19}$ showed that dipolar DMSO molecules participated in proton-acceptor hydrogen bonds with the $\mathrm{C}(4)-\mathrm{OH}$ and $\mathrm{C}(6)-\mathrm{OH}$ group of the laminarin oligomer, inducing very likely changes from triple-stranded structures in water to disordered chains in DMSO.

As mentioned in the Experimental Section, no modifications in the NMR spectra of components were observed when ZEN was dissolved with pure laminarin in DMSO- $d_{6}$. However, use of a specific protocol in which ZEN and laminarin were mixed in water medium under stirring at +39 ${ }^{\circ} \mathrm{C}$ during $1.5 \mathrm{~h}$ followed by freeze-drying prior to DMSO$d_{6}$ solubilization led to spectral modifications in the phenolic region for ZEN. Results showed that the interaction of ZEN and laminarin strongly reduced the hydroxyl groups signals located at $\mathrm{C}(14)$ and $\mathrm{C}(16)$ positions, which were present at $\delta=10.07$ and $\delta=10.86 \mathrm{ppm}$ respectively (Figure 2). The intensity of the signals was sixfold lower compared with the spectrum of ZEN control sample, and the signal was not recovered after the [laminarin $+\mathrm{ZEN}$ ] sample was left for three weeks at room temperature. The intensity was only partially recovered after heating the sample at $+60{ }^{\circ} \mathrm{C}$ during $24 \mathrm{~h}$.

These results clearly favored a specific interaction between ZEN and laminarin chosen as a model of $\beta$ - $(1,3)$-D-glucans. This kind of interaction fully corroborated numerous previous studies dealing with a more macromolecular scale. ${ }^{12,13,20}$

Furthermore, the absence of direct complexation between ZEN and laminarin pure molecules when mixed together in DMSO- $d_{6}$ strongly suggested that the three-dimensional structure of $\beta$-(1,3)-D-glucans was a main factor in ZEN association. We examined this structural aspect using $X$-ray diffraction and molecular modeling.

Wide-Angle X-ray Diffraction Patterns of $\beta$-D-Glucans. The signal resolution of the $2 \theta$ diagrams for curdlan 


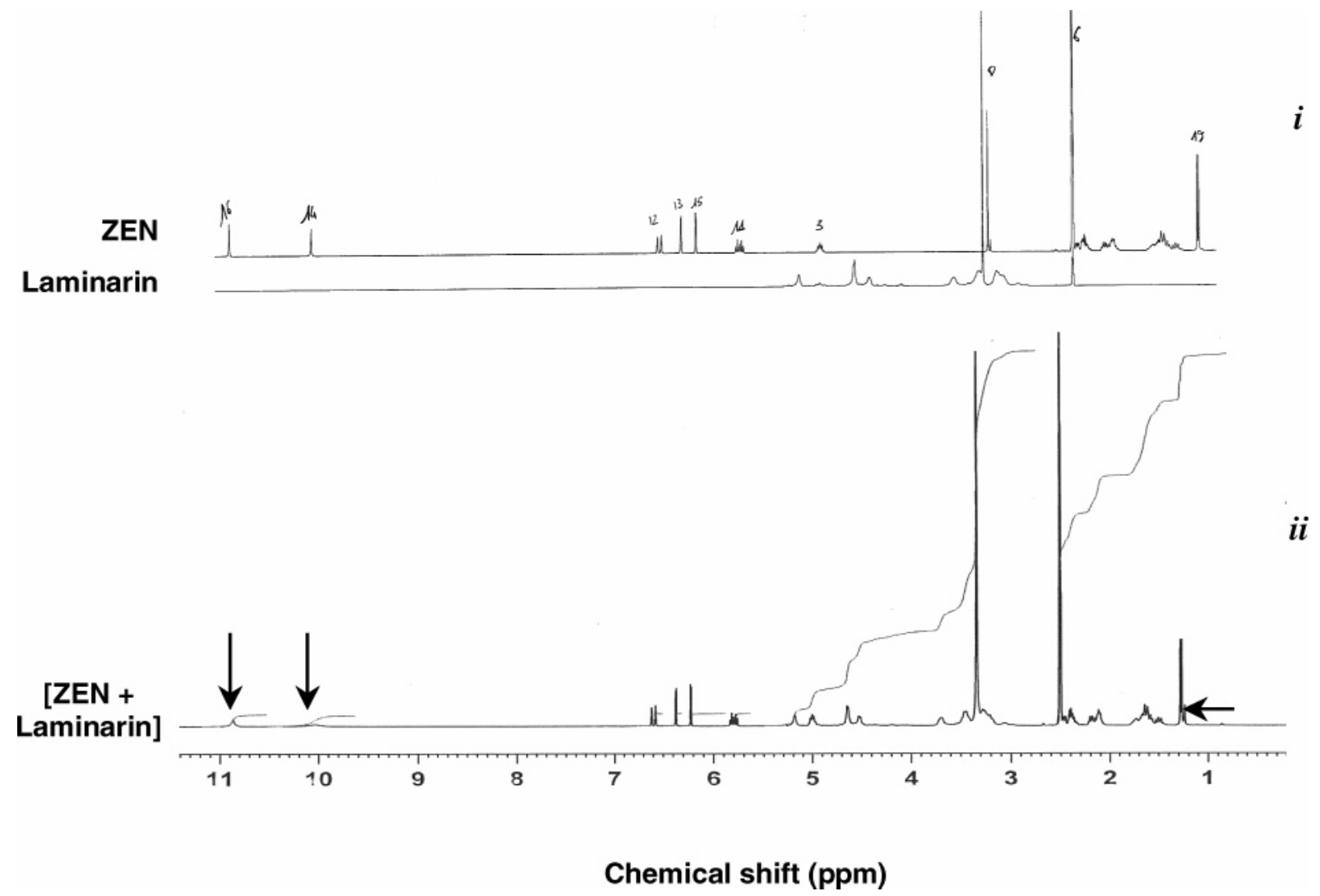

Figure 2. Liquid NMR ${ }^{1} \mathrm{H}$ spectrum acquired on a Bruker $400 \mathrm{MHz}$ prior to (i: simulation) and after interaction (ii) of laminarin polymer toward ZEN realized in DMSO- $d 6$ medium. Arrows highlight the spectral changes.

Table 1. Correspondence between Diffraction Angles $2 \theta$ Measured by X-ray Diffraction and Their Corresponding Reticular Distances $d_{i}$ for Laminarin and Curdlan Molecules in Two Hydration Levels

\begin{tabular}{|c|c|c|c|c|c|c|c|}
\hline \multicolumn{4}{|c|}{ laminarin } & \multicolumn{4}{|c|}{ curdlan } \\
\hline \multicolumn{2}{|c|}{ powder } & \multicolumn{2}{|c|}{$\begin{array}{c}\text { after } \mathrm{BaCl}_{2} \\
\text { hydration }\end{array}$} & \multicolumn{2}{|c|}{ powder } & \multicolumn{2}{|c|}{$\begin{array}{c}\text { after } \mathrm{BaCl}_{2} \\
\text { hydration }\end{array}$} \\
\hline $2 \theta$ & $d_{i}$ & $2 \theta$ & $d_{i}$ & $2 \theta$ & $d_{i}$ & $2 \theta$ & $d_{i}$ \\
\hline $\begin{array}{r}5.52 \\
12.63 \\
18.86 \\
20.88\end{array}$ & $\begin{array}{l}1.60 \\
0.70 \\
0.46 \\
0.43\end{array}$ & $\begin{array}{r}5.45 \\
12.28 \\
18.87 \\
20.60\end{array}$ & $\begin{array}{l}1.62 \\
0.72 \\
0.47 \\
0.43 ; 0.42 ;\end{array}$ & $\begin{array}{r}5.96 \\
11.32 \\
19.21\end{array}$ & $\begin{array}{l}1.46 \\
0.78 \\
0.46\end{array}$ & $\begin{array}{r}5.89 \\
10.65 \\
12.28 \\
16.40\end{array}$ & $\begin{array}{l}1.50 \\
0.83 \\
0.72 \\
0.54\end{array}$ \\
\hline & & & & & & $\begin{array}{l}18.87 \\
20.60\end{array}$ & $\begin{array}{l}0.47 \\
0.43 ; 0.42 ; \\
\quad 0.41 ; 0.38\end{array}$ \\
\hline
\end{tabular}

was enhanced after hydration, by individualization of the different peaks obtained (Table 1). Three versus five peaks were recorded for curdlan respectively for its powder form and $\mathrm{BaCl}_{2}$ hydrated form. Conversely, the hydration with $\mathrm{BaCl}_{2}$ had no impact on the structure of laminarin since the data of the reticular distance only slightly increased between the two samples, and three peaks were obtained in both cases.

Results obtained with curdlan were in agreement with data from the literature, ${ }^{24,25}$ which ascribed the diagram diffraction patterns to a triple-helix association of $\beta$-(1,3)-D-glucan chains and to a cluster of four triple-helix chains. These helical chains were $1.56 \mathrm{~nm}$ apart, and calculation of the fiber period gave an estimated distance of $0.60 \mathrm{~nm}$ between $\beta$-D-glucopyranose units. Thus, chains of $\beta$-(1,3)-D-glucans are organized in helical chains of six $\beta$-D-glucopyranose units per turn of helix. Such organization was assessed and compared for curdlan ${ }^{24-26}$ and the paramylon ${ }^{24} \beta$-(1,3)-D- glucan molecule. Paramylon had reticular distances $\left(d_{i}\right)$ of $1.36,0.78,0.68,0.49$, and $0.45 \mathrm{~nm}$ in hydrated conditions. ${ }^{24}$ Reticular distances found for curdlan were quite similar except for the $1.36 \mathrm{~nm} d_{i}$ value, which was replaced by a signal at $1.50 \mathrm{~nm}$ (Table 1). Consequently, it was proposed that curdlan would involve a more hydrated conformation, which might implicate a more relaxed triple helical conformation compared to paramylon. ${ }^{27,28}$ In this respect, since a higher reticular distance of $1.62 \mathrm{~nm}$ was obtained for laminarin compared to curdlan and no change was recorded in the X-ray signal between the two levels of hydration, we could thus hypothesize a highly hydrated conformation for laminarin, which could implicate highly relaxed triple-helix and/or single-helix organization in both hydrated levels.

In Silico Molecular Mechanics Investigations of $\boldsymbol{\beta}$-DGlucans. Molecular mechanics, performed in a vacuum $(\epsilon$ $=1)$ for the $\beta$-(1,3)-D-glucan dimer, revealed three distinct populated low-energy conformations with high energy barrier between each local minima (Figure 3). Orientations of both primary and secondary hydroxyl groups were also taken into account to set up the most favorable conformation. Dihedral angles of the disaccharide evaluated were $(\varphi) \mathrm{O}-\mathrm{C}(1)-$ $\mathrm{O}(\mathrm{g})-\mathrm{C}\left(3^{\prime}\right)$ and $(\psi) \mathrm{C}(1)-\mathrm{O}(\mathrm{g})-\mathrm{C}\left(3^{\prime}\right)-\mathrm{C}\left(4^{\prime}\right)$, the prime indicating the reducing end. The most stable conformation was found for glycosidic linkage of $[\varphi, \psi]=\left(-100^{\circ},+140^{\circ}\right)$ and an energy of $+2.36 \mathrm{kcal} / \mathrm{mol}$ (conformation (1)). Two other low-energy conformations (2) and (3), respectively) exhibited dihedral angle values of $[\varphi, \psi]=\left(+56^{\circ},+122^{\circ}\right)$ and $[\varphi, \psi]=\left(-98^{\circ},+77^{\circ}\right)$ and energy values of +9.84 and $+9.93 \mathrm{kcal} / \mathrm{mol}$, respectively. 


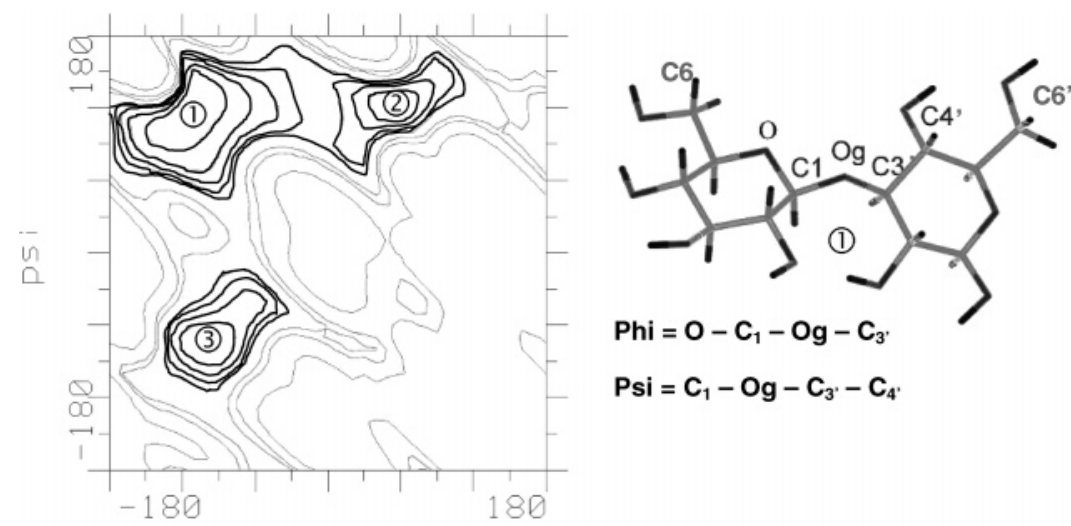

phi

Figure 3. $[\varphi, \psi]$-conformational contour map for the rotation of the $\beta$-D-glucopyranose residues around $(1,3)$ glycosidic bonds $\left(-180\right.$ to $+180^{\circ}$ with a step of $10^{\circ}$ ) obtained with the Biopolymer module of Insight II. Contour lines of local minima are highlighted in black and plotted with energy breaks between lines $\Delta E_{\text {tot }}=2.0 \mathrm{kcal} / \mathrm{mol}$. Contour lines of local maxima (grey) are plotted with $\Delta E_{\text {tot }}=10.0 \mathrm{kcal} / \mathrm{mol}$. The (1) conformation of laminarin dimer is the most stable. Orientation of the primary hydroxyl groups in $\mathrm{C}(6)$ were also taken in account for minimum energy conformation calculation.
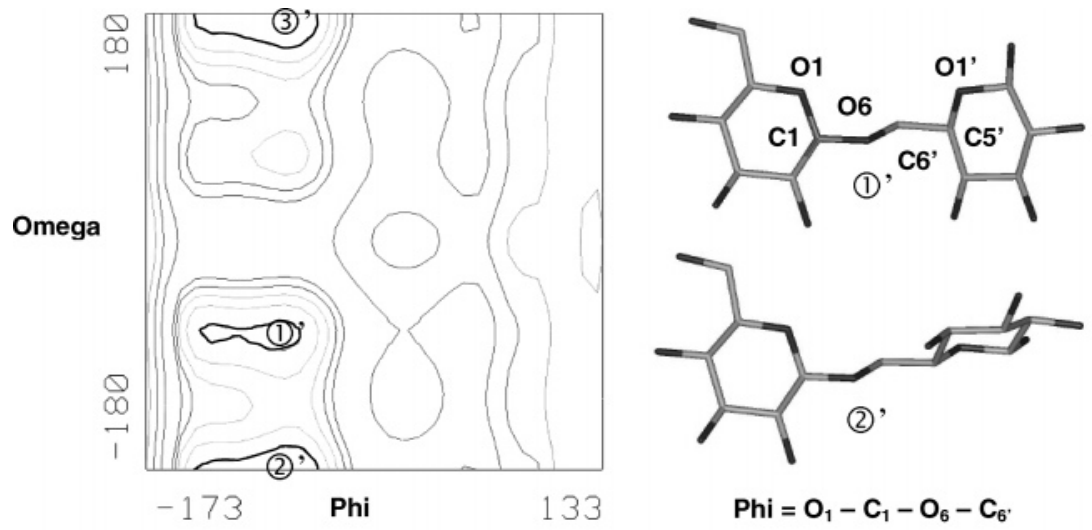

$$
\begin{aligned}
& \mathrm{Phi}=\mathrm{O}_{1}-\mathrm{C}_{1}-\mathrm{O}_{6}-\mathrm{C}_{6^{\prime}}, \\
& \mathrm{Psi}=\mathrm{C}_{1}-\mathrm{O}_{6}-\mathrm{C}_{6^{\prime}}-\mathrm{C}_{5^{\prime},} \\
& \text { Omega }=\mathrm{O}_{6}-\mathrm{C}_{6^{\prime}}-\mathrm{C}_{5^{\prime}}-\mathrm{O}_{1},
\end{aligned}
$$

Figure 4. $[\varphi, \psi, \omega]$-Conformational contour map for the rotation of the $\beta$-D-glucopyranose residues around $\beta$ - $(1,6)$ glycosidic bonds $(-180$ to $+180^{\circ}$ with a step of $10^{\circ}$ ) obtained with the Biopolymer module of Insight II. Dihedral angle value has been set to $85.5^{\circ}$ for $\varphi$. Contour lines of local minima are highlighted in black and plotted with an isocontour of $\Delta E_{\mathrm{tot}}=2.0 \mathrm{kcal} / \mathrm{mol}$. (1)' and (2) dihedral angle values of $\beta$-(1,6) glycosidic bonds were selected for their equal low energy conformation after minimization for $\beta$ - $(1,6)$-D-glucan building.

The low-energy evaluation of $\beta$-(1,6)-D-glucans gave two distinct populated conformations with dihedral angle values for glycosidic linkage of $[\varphi, \psi, \omega]=\left(-87.7^{\circ},+179.9^{\circ}\right.$, $\left.-72,6^{\circ}\right)$ and $[\varphi, \psi, \omega]=\left(-85.5^{\circ},+179.7^{\circ},-177.9^{\circ}\right)$, and energy values of $+7.24 / \mathrm{mol}$ (conformation (1)') and +7.10 $\mathrm{kcal} / \mathrm{mol}$ (conformation (2)'), respectively. Dihedral angles of the disaccharide evaluated were $(\varphi) \mathrm{O}(1)-\mathrm{C}(1)-\mathrm{O}(6)-$ $\mathrm{C}\left(6^{\prime}\right),(\psi) \mathrm{C}(1)-\mathrm{O}(6)-\mathrm{C}\left(6^{\prime}\right)-\mathrm{C}\left(5^{\prime}\right)$, and $(\omega) \mathrm{O}(6)-\mathrm{C}\left(6^{\prime}\right)-$ $\mathrm{C}\left(5^{\prime}\right)-\mathrm{O}\left(1^{\prime}\right)$ (Figure 4). Contrary to $\beta$-(1,3)-D-glucans, the energy barriers between each local minimum for the dimer of $\beta$-(1,6)-D-glucans were low. This indicated the high flexibility of $\beta$-(1,6)-D-glucan chains, which have also been reported in the literature. ${ }^{15}$ Thus, $\beta$ - $(1,6)$-D-glucans were not characterized in solution with an organized conformation like $\beta$-(1,3)-D-glucans. ${ }^{17,29,30}$

The elongation of the structure of $\beta$-(1,3)-D-glucans to a 36 residues molecule gave a simple helix conformation of six $\beta$-D-glucopyranose units per turn after minimization of the structure during 10,000 iterations and fully confirmed the previous X-ray data obtained. The energy value of the chain of $\beta$-(1,3)-D-glucans was equal to around $+46.0 \mathrm{kcal} /$ mol. The branching of $\beta$-(1,6)-D-glucans involved one or three $\beta$-D-glucopyranose residues for each $\beta$-(1,6)-D-glucans chain and used the (1)' or the (2)' low-energy conformations obtained for the dimer molecule. A branching positioning was tested on every $\beta$-D-glucopyranose residue of the $\beta$ - $(1,3)$ D-glucan helix turn, giving rise to five conformational positions (Figure 5). Depending on these positions, the energy values, obtained for (1)' and (2)' low-energy conformations, ranked from +46.6 to +53.8 and +56.4 to $+59.2 \mathrm{kcal} / \mathrm{mol}$, respectively for the $\beta$-(1,3)-D-glucan helix branched with three $\beta$-D-glucopyranose units of $\beta$-(1,6)-D-glucans side chain.

In the following discussion, the results obtained in our study have been compared with those obtained by Frecer et al. ${ }^{19}$ The results found in the literature regarding the localization of the global minimum conformation of the $\beta$-(1,3)-D-glucans dimer are very similar to and conformations but exhibited some differences in the evaluations of dihedral angles, which were found equal to $[\varphi, \psi]=\left(-73^{\circ}\right.$, $\left.+118^{\circ}\right)$ in the literature compared to $[\varphi, \psi]=\left(-100^{\circ}\right.$, $+140^{\circ}$ ) in our study. Such differences could be due to the 

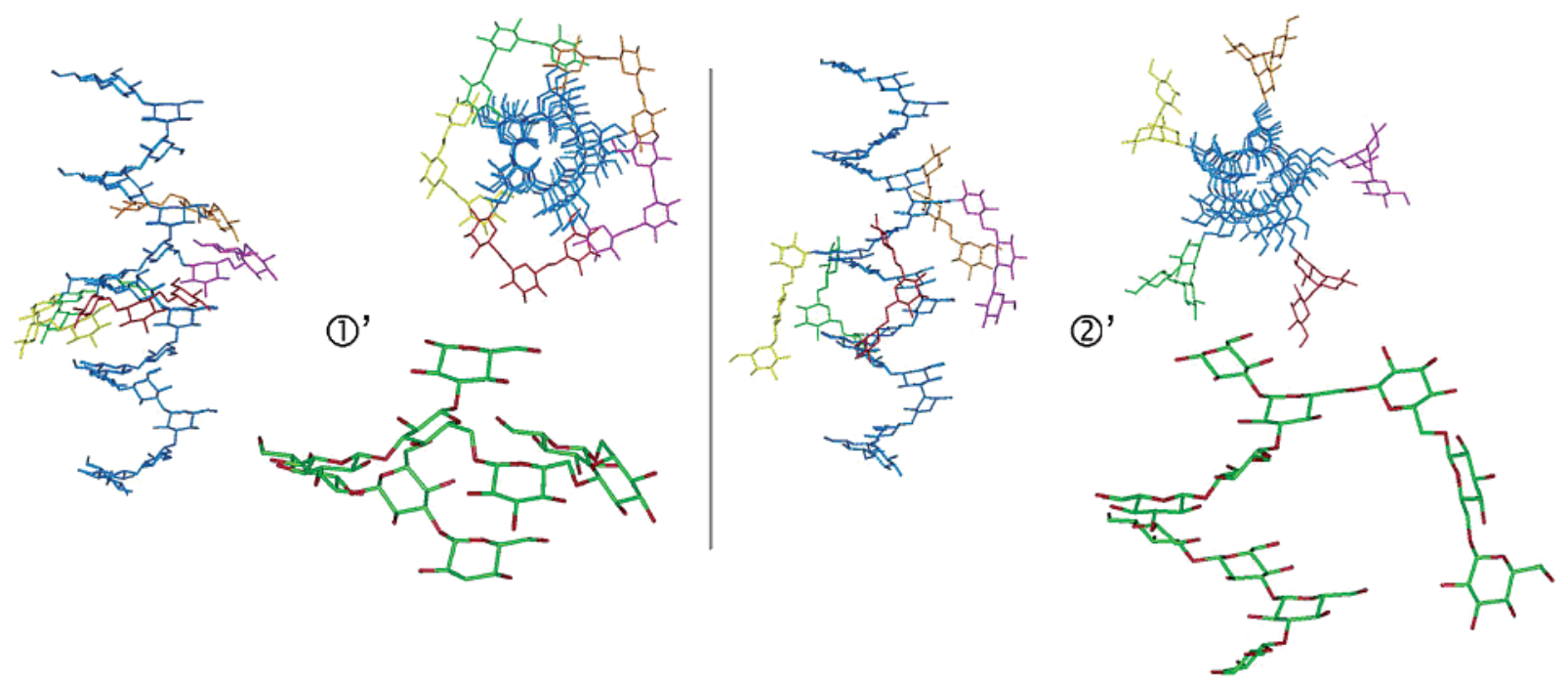

Figure 5. Computer-generated superposed views with the Insight II program of the energy-minimized conformations of the single helix of $\beta$-(1,3)-D-glucans branched with 3 units of $\beta$-D-glucopyranose for the $\beta$-(1,6)-D-glucan side chains in conformation (1) and (2)' and the five positions along the position on the helix turn of the $\beta$-D-glucopyranose unit of the $\beta$ - $(1,3)$-D-glucans chain.

CVFF nature of the force fields used during modeling. These results were also different from others found in the literature with MM3 force fields, ${ }^{31}$ which evaluated angles of $[\varphi, \psi]$ $=\left(-85^{\circ},+78^{\circ}\right)$. However, Frecer et al. ${ }^{19}$ found that the increase of the dielectric constant value to $\epsilon=80$ (solvent conditions) tended to attenuate the energy barriers between the low-energy conformers and decrease the level of the energy found. Such a decrease may be due to the ability of laminarin to form intramolecular and solute-solvent hydrogen bonds. Intramolecular bonds have been identified by molecular dynamics simulation in water and might induce conformation-stabilizing effects attenuating torsional oscillations of glycosidic linkages. However, molecular dynamic trajectories in water have been shown to preserve both vacuum glycosidic bond conformation and the orientation of hydroxyls groups in $\mathrm{C}(4)$ and $\mathrm{C}(6)$ positions. Furthermore, the conformational mobility in the torsion angle space was found to be independent of the number of monosaccharide units in the $\beta$-(1,3)-D-glucan chain. Sometimes a hydrogen bond stabilized the dimer structure of laminaribiose between the hydrogen of the $\mathrm{C}(4)-\mathrm{OH}$ hydroxyl group and the ring oxygen, thus avoiding any other interaction for the free hydroxyl group. The intramolecular stabilizing bond could be inhibited by the effect of adducts formation with DMSO on the $\mathrm{C}(4)-\mathrm{OH}$ hydroxyl group, thus disturbing the spatial organization of the helical $\beta$-(1,3)-D-glucan molecule.

In Silico Molecular Mechanics Investigations of ZEN. Two stable, semi-relaxed conformations for the ZEN molecule were found after minimization within 8,500 iterations in a vacuum (Figure 6). The A and B structures exhibited low-energy conformations of -24.03 and $-24.84 \mathrm{kcal} / \mathrm{mol}$, respectively. Molecular modeling of ZEN was achieved by comparing the conformations obtained with both X-ray diffraction studies ${ }^{23}$ and investigations on the structure of ZEN in solution by high-field NMR and molecular modeling analysis. ${ }^{18}$ It was thus confirmed that the B structure was the conformation found for ZEN in crystalline and aqueous conditions. The B conformation was characterized by the orientation of the ketone group located at $\mathrm{C}(7)$ outside of

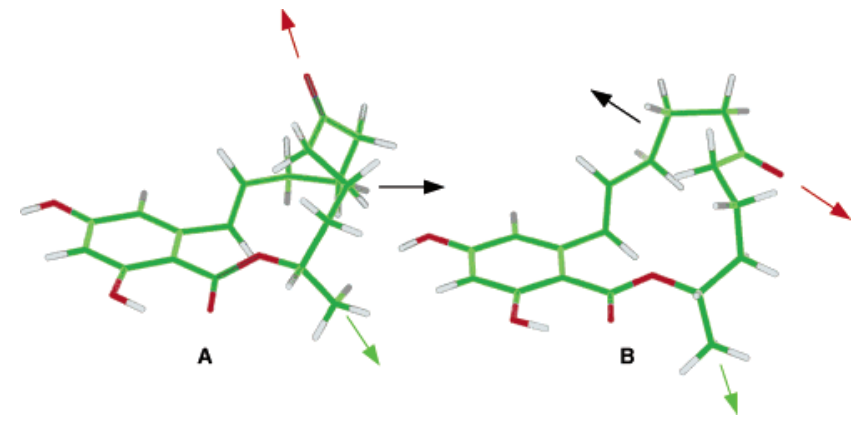

Figure 6. Computer-generated views with the Insight II program of the energy-minimized conformations of ZEN molecule. Arrows indicate discrepancies between the orientations of the different chemical groups of the two resulting conformations: $\mathrm{C}(3)$ in green, $\mathrm{C}(5)$ in black, and $\mathrm{C}(7)$ in red.

the molecule and in the same orientation when compared to the methyl group located at $\mathrm{C}(19)$. The molecule consisted of a $\mathrm{C}(13)$ to $\mathrm{C}(18)$ phenyl ring fused to a 14-membered lactone ring. Furthermore, $\mathrm{X}$-ray diffraction has characterized intramolecular potential hydrogen bonds resulting in stabilization of the general conformation of the toxin. The hydroxyl group of the phenyl moiety located at $\mathrm{C}(16)$ interacted with the $\mathrm{O}$-carbonyl atom located at $\mathrm{C}(1)$, forming a strong intramolecular $\mathrm{O}-\mathrm{H} \cdots \mathrm{O}$ hydrogen bond, which created a new six-membered ring. In addition, there are four other intramolecular $\mathrm{C}-\mathrm{H} \cdots \mathrm{O}$ hydrogen bonds, which internally stabilize the molecule conformation. ${ }^{23}$ Cordier et al. ${ }^{18}$ confirmed these results by using NOE difference spectroscopy experiments in aqueous medium, which characterized that the double bond between $\mathrm{C}(12)$ and $\mathrm{C}(13)$ atoms was preferentially pulled into coplanarity with the macro-ring, and consequently the lactone bent out of the plane. Thus, the ketone group was not able to conjugate with the aromatic moiety. Finally, the hydroxyl group at $\mathrm{C}(14)$ and at $\mathrm{C}(16)$ as well as the ketone group located at $\mathrm{C}(7)$ could become potential acceptor sites of intermolecular bonds with ZEN molecules. Furthermore, the molecular geometry of ZEN in solution and in the solid state was essentially the same. 
Table 2. Energy Values Obtained for Docking after Minimization with Insight II Software of the ZEN Molecule (B Conformation) into the Single-Helix of $\beta$-(1,3)-D-Glucan Chain ${ }^{a}$

\begin{tabular}{|c|c|c|c|c|c|c|}
\hline \multirow{3}{*}{$\begin{array}{c}\beta \text {-(1,3)-D-glucans added to } \\
\beta \text {-(1,6)-D-glucan conformation }\end{array}$} & & \multicolumn{5}{|c|}{ energy (kcal/mol) } \\
\hline & & \multicolumn{2}{|c|}{$1 \times \beta(1,6)$-D-glucans } & \multicolumn{2}{|c|}{$3 \times \beta(1,6)$-D-glucans } & \multirow{2}{*}{$\frac{5 \times \beta(1,6) \text {-D-glucans }}{(2)^{\prime}}$} \\
\hline & & (1)' & (2)' & (1)' & (2) & \\
\hline complex energy & -19.3 & -19.4 & -21.1 & -30.6 & -13.0 & -5.45 \\
\hline glucan energy & +47.7 & +53.6 & +52.6 & +47.0 & +61.1 & +69.7 \\
\hline $\begin{array}{l}\text { ZEN energy } \\
\text { docking energy: }\end{array}$ & -19.3 & -20.3 & -20.5 & -20.7 & -20.4 & -20.5 \\
\hline van der Waals & -36.6 & -40.2 & -40.2 & -44.6 & -42.4 & -43.7 \\
\hline electrostatic & -11.0 & -12.5 & -12.9 & -12.3 & -11.3 & -11.0 \\
\hline total & -47.6 & -52.7 & -53.2 & -56.9 & -53.7 & -54.7 \\
\hline
\end{tabular}

a The simple helix of $\beta$ - $(1,3)$-D-glucans is branched with one and three $\beta$-D-glucopyranose units for the $\beta$ - $(1,6)$-D-glucan side chain in conformation (1) and (2)'; the single-helix of $\beta$-(1,3)-D-glucan chain is branched with five $\beta$-D-glucopyranose units of $\beta$ - $(1,6)$-D-glucan side chain in (2)' conformation.

In Silico Molecular Docking of ZEN inside the $\beta$-DGlucans Structure. The complete set of energy valuesthe $\beta$-D-glucan energy, the ZEN energy, the complex energy, and the docking energy-are compiled in Table 2. Among the numerous complexes, the selection cannot be made, in any case, on the assessment of a single energy value, whatever the complex energy, the $\beta$-D-glucan energy, the toxin energy, or the docking energy. None of these energy values is pertinent enough in itself to constitute the ultimate criterion of selection. Each complex must be compared to its counterpart with its complete set of energies and only after a careful examination of the whole set of values can the selection become relevant.

Docking of the ZEN molecule inside the $\beta$-D-glucan structure could be a two-step mechanism: (i) ZEN could be trapped inside the simple helix of the $\beta$-(1,3)-D-glucan chain; (ii) the branched $\beta$-(1,6)-D-glucan chain could cover the toxin molecule and maintain it inside the helix. In that sense, the branched $\beta$-(1,6)-D-glucans could be considered as an enlarged binding site expanding outside of the main $\beta$ - $(1,3)$ D-glucan chain.

Several positions, testing the different orientations of the toxin inside the $\beta$-(1,3)-D-glucan single-helix, were found and gave energy values for A and B ZEN conformations ranking from -22.9 to -44.2 and -22.9 to $-47.6 \mathrm{kcal} / \mathrm{mol}$, respectively. Thus, the $\mathrm{B}$ conformation, which has also been found to be the native conformation of ZEN, ${ }^{18,23}$ was more stable than the A conformation inside the $\beta$-D-glucan helix. The lowest docking energy value obtained $(-47.6 \mathrm{kcal} / \mathrm{mol})$ was divided into $-36.6 \mathrm{kcal} / \mathrm{mol}$ of van der Waals interaction and $-11.0 \mathrm{kcal} / \mathrm{mol}$ of electrostatic contribution (Table 2). The latter value accounted for the occurrence of three to four hydrogen bonds during interaction, identified in Figure 7. Considering both the position of the glucose units inside the helical structure of $\beta$-(1,3)-D-glucan and the ZEN positioning, there is high evidence for an hydrogen bond to occur between the hydroxyl group located at $\mathrm{C}(6)$ of the 6th $\beta$-D-glucopyranose residue and the ketone group located at $\mathrm{C}(7)$ of the ZEN molecule. The hydroxyl group located at $\mathrm{C}(16)$ is involved in an intramolecular stabilizing hydrogen bond with the O-carbonyl atom located at C(1) of the ZEN molecule. The O-carbonyl could also be implicated in an intermolecular bond with the hydroxyl group located at $\mathrm{C}(2)$ of the 3 rd $\beta$-Dglucopyranose residue. Furthermore, a stabilizing effect due to the electronic interaction was revealed by the geometrical
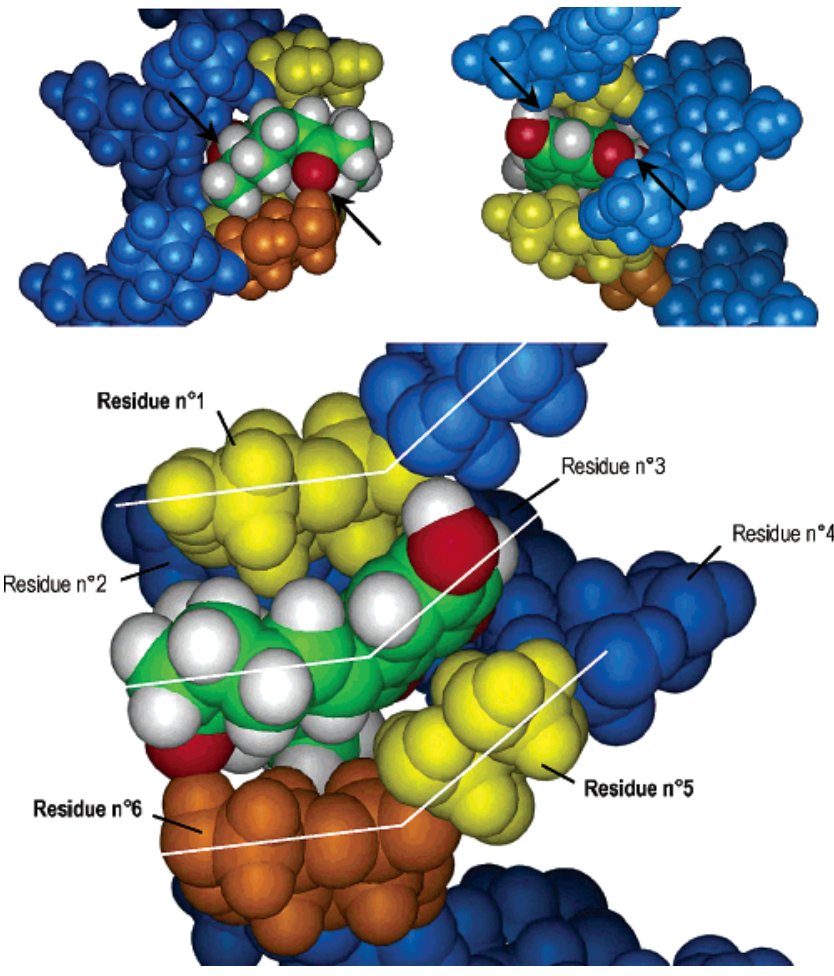

Figure 7. Computer-generated views with the Insight II program of the energy-minimized structure of the docking of the most favorable conformation of ZEN (B) into the single-helix of $\beta$-(1,3)-D-glucan chain. Arrows indicate hydrogen bonds involved in the interaction. Lines highlights the steric complementarity between ZEN and $\beta$-(1,3)-Dglucan geometry.

symmetry and proximity of the $\beta$-D-glucopyranose ring of the 1 st and the 5 th residue of the $\beta$-(1,3)-D-glucan helix and the phenol moiety of ZEN giving a stacking effect with a high van der Waals energy value $(-36.6 \mathrm{kcal} / \mathrm{mol})$.

The branching of one to five $\beta$-D-glucopyranose residues to the $\beta$-(1,3)-D-glucan helix decreased the energy values and thus increased the stability of the interaction for both (1)' and (2)' low-energy conformations of $\beta$-(1,6)- glucosidic linkage (Table 2). The (1)' conformation appeared to have a larger stabilizing effect than the (2)' conformation after addition of three $\beta$-D-glucopyranose residues, exhibiting energy values of -56.9 and $-53.7 \mathrm{kcal} / \mathrm{mol}$, respectively, while no significant difference between (1)' and (2)' conformations was noted after the addition of only one $\beta$-Dglucopyranose unit. However, it is noteworthy to mention 

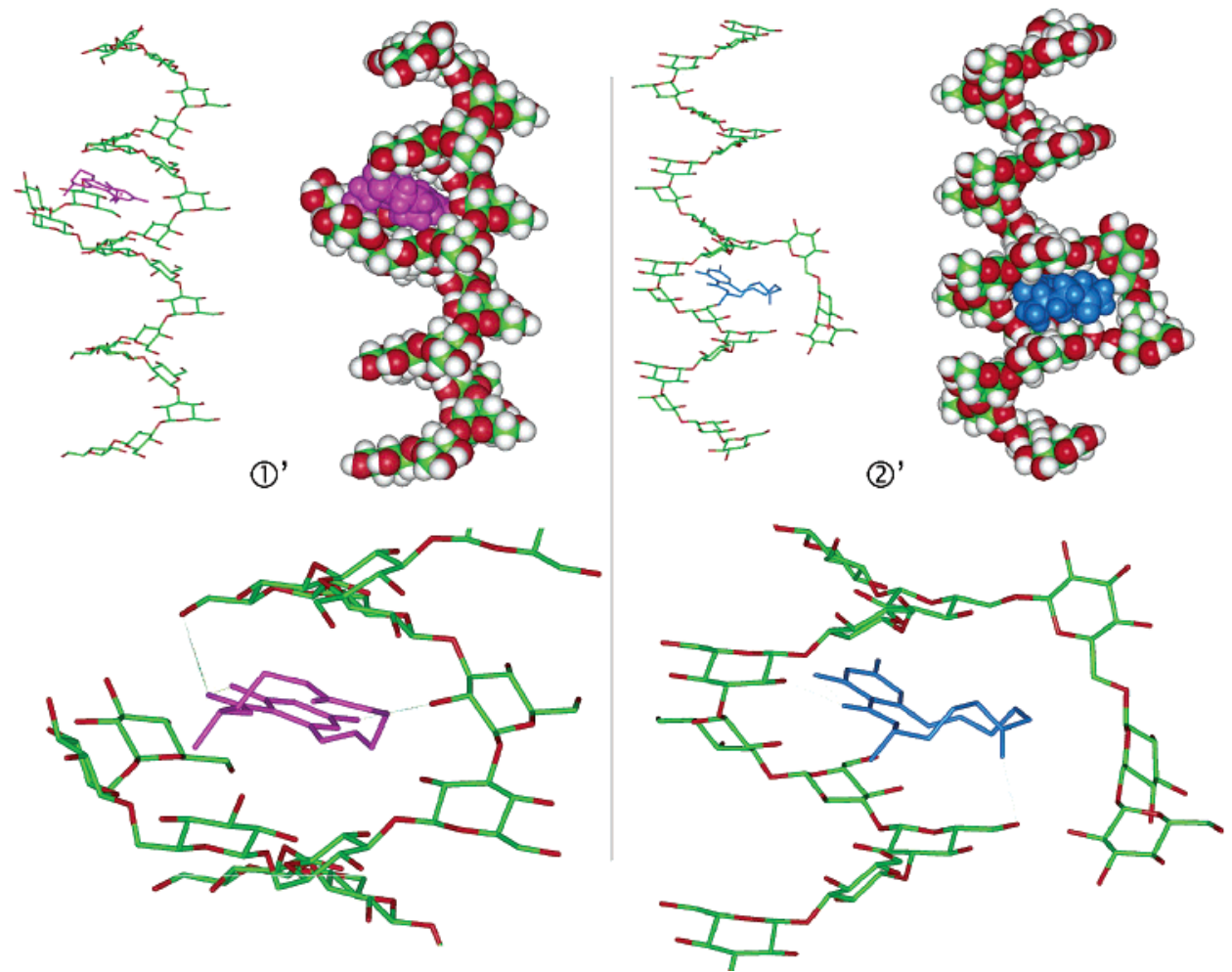

Figure 8. Computer-generated views with the Insight II program of the energy-minimized structure of the docking of the most favorable conformation of ZEN (B) into the single-helix of $\beta$-(1,3)-D-glucan chain branched with three $\beta$-D-glucopyranose moieties of $\beta$-(1,6)-D-glucan side chain, respectively in (1)' and (2)' conformations.

that only the (2)' conformation was able to lead to the branching of a five residues $\beta$-(1,6)-D-glucan chain, when the (1)' conformation, elongated also to a five residues $\beta$-(1,6)-chain, induced important steric clashes with the $\beta$-(1,3)-D-glucan helix. The addition of five residues also improved the stability of the complex, decreasing the energy value from -53.7 to $-54.7 \mathrm{kcal} / \mathrm{mol}$. Furthermore, we observed that there was no significant change in electrostatic energy during addition of $\beta$-D-glucopyranose residues to the $\beta$-(1,6)-D-glucan chain and that only the van der Waals energy was decreased. In this respect, the addition of the $\beta$ - $(1,6)$-D-glucan side chain did not induce hydrogen bond formation but was preferentially involved in hydrophobic interactions with the ZEN molecule. These interactions could probably involve symmetrical geometries between the $\beta$-Dglucopyranose ring and the macrocycle of ZEN, as shown in Figure 8. The (1)' conformation exhibited intermolecular hydrogen bond network involving the hydroxyl group located at $\mathrm{C}(14)$ of the ZEN molecule and the hydroxyl group located at $\mathrm{C}(2)$ of a $\beta$-D-glucopyranose unit. Either the hydroxyl group located at $\mathrm{C}(16)$ involved an intramolecular stabilizing bond with the O-carbonyl atom located at $\mathrm{C}(1)$ of the ZEN molecule or/and the latter is involved in an intermolecular bond with the hydroxyl group located at $\mathrm{C}(6)$ of a $\beta$-Dglucopyranose residue. The (2)' conformation exhibited intermolecular hydrogen bonding involving the ketone group located at $\mathrm{C}(7)$ of the ZEN molecule and the hydroxyl group located at $\mathrm{C}(6)$ of a $\beta$-D-glucopyranose unit. The hydroxyl group located at $\mathrm{C}(16)$ involved the previously indicated intramolecular bond and the O-carbonyl atom located at $\mathrm{C}(1)$ involved in an intermolecular bond with the hydroxyl group located at $\mathrm{C}(6)$ of a $\beta$-D-glucopyranose residue. It was noted that the branching of five $\beta$-D-glucopyranose residues in conformation (2)' could lead to the formation of helical structure of the $\beta$-(1,6)-D-glucan side chain, which could in turn be stabilized by the involvement of a hydrogen bond between both hydroxyls located at $\mathrm{C}(4)$ of the 4 th residue of $\beta$-(1,6)-D-glucans and the $\beta$-(1,3)-D-glucan chain (Figure 9 ). These results could explain the tremendous stability of the complex with the formation of an encaging site of interaction for the ZEN molecule.

Interestingly, these calculations, using molecular mechanics technics, strongly evidenced the geometrical, the electrostatic and the hydrophobic complementarities between the $\beta$-D-glucans, branched or not, and the ZEN toxin. Previous macromolecular in vitro experiments ${ }^{12,13,20}$ and NMR experiments established that environmental conditions such as $\mathrm{pH}$ and nature of the solvent can decrease the stability of the geometry of $\beta$-D-glucans, and induce low abilities of complex-forming toward ZEN. It appeared that the single helical conformation played the major role in the complexation process. Although the triple helical conformation has not yet been tested, we could reasonably hypothesize that the triple helix will not evidence inner helix space, large enough to fill with any other molecule than water molecules. Since the single-helix complexes the ZEN deeply inside its helix, an internal complex between the triple helix and the ZEN is thus highly hypothetical. In this respect, triple helical structure would only display surface adsorptive properties toward ZEN, which might be less stable in relation to environmental changes. As explained before, the complexation integrated a cooperative behavior between the amounts of ZEN initially added in the medium versus the amount bound by $\beta$-D-glucans. Furthermore, the measurement of 

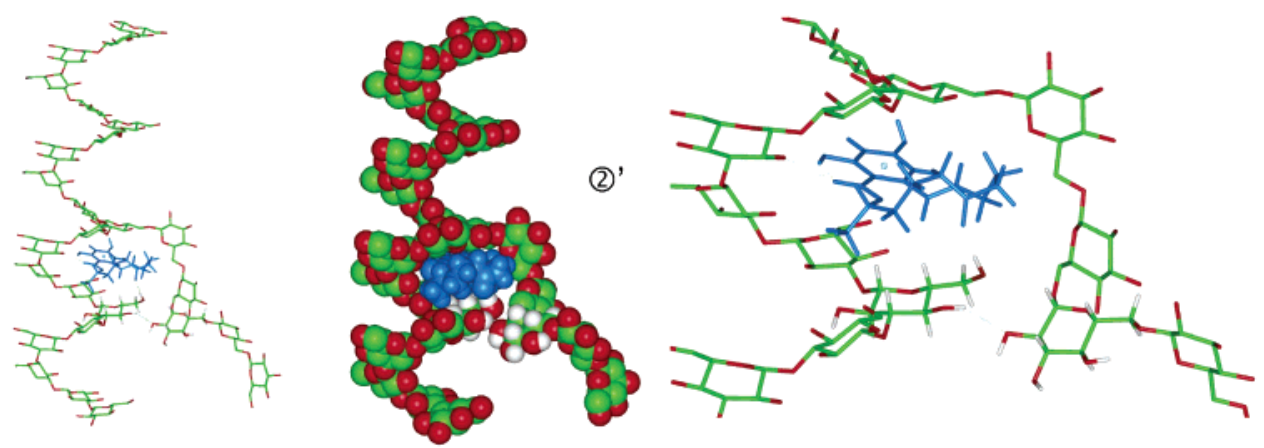

Figure 9. Computer-generated views with the Insight II program of the energy-minimized structure of the docking of the most favorable conformation of ZEN (B) into the single-helix of $\beta$-(1,3)-D-glucan chain branched with five $\beta$-D-glucopyranose moieties of $\beta$ - $(1,6)$-D-glucan side chain, (2)' conformation.

slight variations in the energy of the $\beta$-D-glucan chain considered alone could implicate structural modifications on $\beta$-D-glucans by opening or hiding other anchoring sites for ZEN. However, docking trials of two ZEN molecules inside the $\beta$-(1,3)-D-glucan helix did not demonstrate any synergy or interference influence in the setting up of the interaction due to their synchronized arrival or due to the arrival of a second ZEN molecule on a $\beta$-(1,3)-D-glucan helix, which had already interacted with a first ZEN molecule. The energy value of the complex was equal to $-45 \mathrm{kcal} / \mathrm{mol}$ for both cases. Thus, our results did not elucidate the cooperative nature of the complexation phenomenon, which might implicate the complexity of the $\beta$-D-glucan network at a more macromolecular level. Furthermore, $\beta$-(1,6)-D-glucans, which are generally present in low amounts in yeast cell wall, could account for high amounts in some mutants. If branched chains of these $\beta$-(1,6)-D-glucans increased in length, they could form helical chains with much higher flexibility than $\beta$-(1,3)-D-glucans, as evidenced in molecular modeling. $\beta$-(1,6)-D-glucans could then increase their complexation abilities toward ZEN and perhaps could contribute to increase the cooperative behavior of the $\beta$-D-glucan network due to intrinsic adaptability.

\section{Conclusions}

Merged with previous work, ${ }^{12,13,20}$ this study clearly elucidates the major role played by the single helical conformation of $\beta$-(1,3)-D-glucans toward ZEN complexation. Beyond extraordinary steric complementarities, stable intermolecular hydrogen bonds are created which involved the hydroxyl and ketone groups of the ZEN molecule plus the hydroxyl groups located at $\mathrm{C}(4), \mathrm{C}(6)$ and, to a lesser extent, at $\mathrm{C}(2)$ hydroxyl group of the $\beta$-(1,3)-D-glucan molecule. Interestingly, the significant implication of a stacking effect has been characterized between the phenyl moiety of ZEN and two opposite $\beta$-D-glucopyranose residues of the single-helix of $\beta$-(1,3)-D-glucans through geometrical symmetry between the two molecules. In addition, the increasing length of $\beta$-(1,6)-D-glucan side chains seemed to exhibit stabilizing effects by enhancing the van der Waals interactions with ZEN. These theoretical findings were in full agreement with the structural parameters found either for ZEN ${ }^{18,23}$ and $\beta$-D-glucans in natural conditions. ${ }^{15,17,24} \mathrm{As}$ far as we know, this is the first study that elucidates how
$\beta$-D-glucan chains have specific and quantitative affinity for ZEN and could largely contribute to prove the reliability of these adsorbents in the fight against mycotoxins.

However, in vivo application of $\beta$-D-glucans as feed additives would require the use of insoluble yeast cell wall $\beta$-D-glucans, which are not adsorbed in the digestive tract. The physical and chemical properties of yeast matter and yeast cell wall can be controlled through the conditions in use for biomass production. Also, the treatment and extraction processes used to prepare the cell wall material are of major importance for the quality and properties of $\beta$-Dglucans. Adsorption abilities are greatly increased by the highly complex spatial organization of yeast cell wall due to the involvement of very densely organized structures. Also, $\beta$-D-glucans from yeast cell wall must remain nondegraded in the digestive tract of animals. This is why a complex structure of the organic adsorbent is recommended for in vivo use.

Acknowledgment. This work was co-supported (CIFRE No. 704/2,000) by Alltech Company, the ANRT (Association Nationale de la Recherche Technique) and INRA. We give special thanks to Bruno Pontoire for helpful support in the X-ray diffraction measurement of $\beta$-D-glucans (UR783 INRA, Nantes, France) and to Pierre Galtier (INRA-UR66, Toulouse, France), Laurent Poughon and Claude-Gilles Dussap (CUST, Université Blaise-Pascal, Clermont-Ferrand, France) for their helpful personal involvement in the setting up of this research.

\section{References and Notes}

(1) CAST Mycotoxins: Risks in plant, animal, and human systems; Council for Agricultural Science and Technology: Ames, Iowa, 2003.

(2) Yiannikouris, A.; Jouany, J.-P. Anim. Res. 2002, 51, 81.

(3) Grant, P. G.; Phillips, T. D. J. Agric. Food Chem. 1998, 46, 599.

(4) Lemke, S. L.; Ottinger, S. E.; Mayura, K.; Ake, C. L.; Pimpukdee, K.; Wang, N.; Phillips, T. D. Anim. Feed Sci. Technol. 2001, 93, 17.

(5) Devegowda, G.; Raju, M. V. L. N.; Afzali, N.; Swamy, H. V. L. N. Biotechnology in the Feed Industry; Nottingham University Press: Nottingham, U.K., 1998; p 241.

(6) Newman, K. Biotechnology in the Feed Industry; Nottingham University Press: Nottingham, U.K., 2000; p 369.

(7) Dawson, K. A.; Evans, J.; Kudupoje, M. Science and Technology in the Feed Industry; Nottingham University Press: Nottingham, U.K., 2001; p 169.

(8) Freimund, S.; Sauter, M.; Rys, P. J. Environ. Sci. Health B 2003, $38,243$.

(9) El-Nezami, H.; Mykkanen, H.; Kankaakpää, P.; Salminen, S.; Ahokas, J. J. Food Prot. 2000, 63, 549. 
(10) El-Nezami, H.; Polychronaki, N.; Salminen, S.; Mykkanen, H. Appl. Environ. Microbiol. 2002, 68, 3545.

(11) El-Nezami, H.; Chrevatidis, A.; Auriola, S.; Salminen, S.; Mykkanen, H. Food Addit. Contam. 2002, 19, 680.

(12) Yiannikouris, A.; François, J.; Poughon, L.; Dussap, C.-G.; Bertin, G.; Jeminet, G.; Jouany, J.-P. J. Food Prot. 2004, 67, 1195.

(13) Yiannikouris, A.; François, J.; Poughon, L.; Dussap, C.-G.; Bertin, G.; Jeminet, G.; Jouany, J.-P. J. Agric. Food Chem. 2004, 52, 3666

(14) Yiannikouris, A.; François, J.; Poughon, L.; Dussap, C.-G.; Jeminet, G.; Bertin, G.; Jouany, J.-P. J. Food Prot. 2004, (accepted).

(15) Kogan, G. Studies in Natural Products Chemistry; Elsevier Science B. V.: Karachi, Pakistan, 2000; p 107.

(16) Young, S. H.; Dong, W. J.; Jacobs, R. R. J. Biol. Chem. 2000, 275, 11874.

(17) Kim, Y.-T.; Kim, E.-H.; Cheong, C.; Williams, D. L.; Kim, C.-W.; Lim, S.-T. Carbohydr. Res. 2000, 328, 331.

(18) Cordier, C.; Gruselle, M.; Jaouen, G.; Hughes, D. W.; McGlinchey, M. J. Magn. Reson. Chem. 1990, 28, 835.

(19) Frecer, V.; Rizzo, R.; Miertus, S. Biomacromolecules 2000, 1, 91.

(20) Yiannikouris, A.; Poughon, L.; Cameleyre, X.; Dussap, C.-G.; François, J.; Bertin, G.; Jouany, J.-P. Biotechnology Lett. 2003, 25, 783
(21) André, G.; Buléon, A.; Juy, M.; Aghajari, N.; Haser, R.; Tran, V. Biopolymers 1999, 49, 107.

(22) André, G.; Buléon, A.; Haser, R.; Tran, V. Biopolymers 1999, 50, 751.

(23) Panneerselvam, K.; Rudino-Pinera, E.; Soriano-Garcia, M. Acta Crystallogr. Sect. C 1996, 52, 3095.

(24) Chuah, C. T.; Sarko, A.; Deslandes, Y.; Marchessault, R. H. Macromolecules 1983, 16, 1375.

(25) Okuyama, K.; Obata, Y.; Noguchi, K.; Kusaba, T.; Ito, Y.; Ohno, S. Biopolymers 1996, 38, 557.

(26) Okuyama, K.; Otsubo, A.; Fukuzawa, Y.; Ozama, M.; Harada, T.; Kasai, N. J. Carbohydr. Chem. 1991, 10, 645.

(27) Marchessault, R. H.; Deslandes, Y.; Ogawa, K.; Sundararajan, P. R. Can. J. Chem. 1977, 55, 300.

(28) Marchessault, R. H.; Deslandes, Y. Carbohydr. Res. 1979, 75, 231

(29) Manners, D. J.; Masson, A. J.; Patterson, J. C.; Björndal, H.; Lindberg, B. Biochem. J. 1973, 135, 31.

(30) Stevens, E. S.; Sathyanarayana, B. K. Carbohydr. Res. 1987, 160 , 131.

(31) Dowd, M. K.; French, A. D.; Reilly, P. J. Carbohydr. Res. 1992, $233,15$.

BM049775G 